\title{
Implementation and experience of an innovative smart patient care system: a cross-sectional study
}

Ming-Huan Wen ${ }^{12^{*}}$, Dorothy Bai ${ }^{3}$, Shirling Lin ${ }^{1}$, Chi-Jen $\mathrm{Chu}^{4}$ and Yeh-Liang Hsu ${ }^{3,5}$

\begin{abstract}
Background: Although a patient care system may help nurses handle patients' requests or provide timely assistance to those in need, there are a number of barriers faced by nurses in handling alarms.

Methods: The aim of the study was to describe the implementation and experience of an innovative smart patient care system (SPCS). This study applied a cross-sectional descriptive design. We recruited 82 nurses from a medical center in Taiwan, with 25 nurses from a ward that had introduced an SPCS and 57 nurses from wards that used the traditional patient care system (TPCS). The major advantages of the SPCS compared to the TPCS include the specification of alarm purposes, the routing of alarms directly to the mobile phone; the capability of immediate communication via phone; and three-stage bed-exit alerts with low false alarm rate.
\end{abstract}

Results: Approximately $56 \%$ of nurses in the TPCS wards perceived that the bed-exit alert was easily ignorable, while this rate was reduced to $32 \%$ in the SPCS ward. The immediate communication via phone was considered as the most helpful function of the SPCS, with a weighted average score of 3.92/5, and $52 \%$ of nurses strongly agreed (5/5) that this function was helpful. The second-highest ranked function was the three-stage bed-exit alert, with an average score of $3.68 / 5$, with approximately $24 \%$ of nurses strongly agreeing $(5 / 5)$ that this function was helpful. The average response time using TPCS was $145.66 \mathrm{~s}$ while it was $59.02 \mathrm{~s}$ using the SPCS $(P<.001)$. Among the 110 observed alarms in the SPCS ward, none of them were false bed-exit alarms. In comparison, among 120 observed alarms in the TPCS wards, $42(35 \%)$ of them were false bed-exit alarms $(P<.001)$. In this study, we found that $30.91 \%$ of alarms using SPCS were processed because nurses received and responded to the alert via mobile phone.

Conclusions: A smart patient care system is needed to help nurses make more informed prioritization decisions between responding to alarms and ongoing tasks and finally assist them in adjusting their work in various situations to improve work efficiency and care quality.

Keywords: Nurse call system, Patient care system, Implementation, Patient communication, False alarm, Bed exit

\section{Introduction}

Patient care systems have been commonly used in hospitals. 'A system of call bell', described by Florence Nightingale in the mid-nineteenth century, may be one of the

\footnotetext{
*Correspondence: mhwen@vghtpe.gov.tw

'Department of Nursing, Taipei Veterans General Hospital, Taipei, Taiwan.

${ }^{2}$ School of Nursing, National Yang Ming Chiao Tung University, Taipei, Taiwan

Full list of author information is available at the end of the article
}

earliest patient care or nurse call system concepts [1]. Although the forms of the patient care system vary from a drawstring-bell system to a computer-based system, the core function of notifying nurses that a patient needs their assistance remains. Existing findings show that the patient care system helps patients feel safe, increases their control of the situation, and achieves successful recovery [2-4]. Information transferred by the patient care system

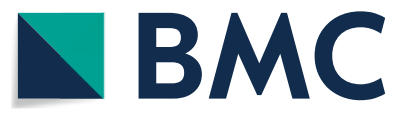

(c) The Author(s) 2022. Open Access This article is licensed under a Creative Commons Attribution 4.0 International License, which permits use, sharing, adaptation, distribution and reproduction in any medium or format, as long as you give appropriate credit to the original author(s) and the source, provide a link to the Creative Commons licence, and indicate if changes were made. The images or other third party material in this article are included in the article's Creative Commons licence, unless indicated otherwise in a credit line to the material. If material is not included in the article's Creative Commons licence and your intended use is not permitted by statutory regulation or exceeds the permitted use, you will need to obtain permission directly from the copyright holder. To view a copy of this licence, visit http://creativecommons.org/licenses/by/4.0/. The Creative Commons Public Domain Dedication waiver (http://creativeco mmons.org/publicdomain/zero/1.0/) applies to the data made available in this article, unless otherwise stated in a credit line to the data. 
has been found to allow for timely information transfer, increase the timeliness of patient care, enhance problemsolving abilities, and facilitate teamwork among nurses [5].

In addition, the patient care system plays an important role in improving patient safety from the perspective of both nurses [6] and patients [7]. For example, patient falls are a significant issue in clinical settings [8-10]. The Centers for Medicare and Medicaid Services in the US have stopped paying for preventable hospital falls in 2008, which has raised more awareness of and efforts toward fall prevention in hospitals [11, 12]. Falls commonly occur between $5 \mathrm{pm}$ and $7 \mathrm{am}$ in a patient's room, when staffing levels are lower, and a large number of falls are related to getting in and out of bed [13]. The modern patient care system often consists of a bed-exit alert that is automatically launched when a patient at risk of falling leaves the bed so that nurses can provide assistance when necessary.

Although the patient care system may help nurses handle patients' requests or provide timely assistance to those in need, there are a number of barriers faced by nurses in handling alarms. Nurses have multiple clinical and administrative tasks, and the patient care system, by nature, is an interruption of ongoing tasks [14-16]. In human-computer interactions, interruptions have been found to negatively affect human cognition [17], which may negatively influence patient safety. Evidence has shown the relationships between interruptions and medical errors [17-19]. Conversely, not all interruptions caused by alarms are unwanted, and some are even desired to provide quality care $[14,20]$. Among all the possible reasons behind alarms, such as information requirements, pain management, and toilet assistance, it has been shown that less than one-third of all nurse calls are considered serious or urgent $[4,6,21]$. Given that nurses have multiple tasks to handle, it is difficult and stressful for nurses to make decisions regarding whether or not to abort an ongoing task to handle an alarm [14].

With limited information on an alarm provided by patient care systems, nurses tend to lower their prioritization in responding to it $[14,22]$. There are some other barriers, such as limited access to an alarm if it is only displayed in fixed places, such as monitors in the corridor or at nursing stations [23], a lack of ways to share alarm-responding responsibilities with colleagues [24], and insufficient time to respond to a bed-exit alert [25]. Responding to the demands of the current situation implies dealing with reality, which is an organizational ability [26]. To achieve this goal, a resilient patient care system is needed to help nurses make better decisions in various conditions and cope with the interruption to their work brought about by responding to an alarm.
To date, limited evidence has been reported on resilient patient care systems designed with adaptive capacity that help nurses handle alarms [14].

The study aimed to describe the implementation and experience of an innovative smart patient care system (SPCS). The primary objectives were to compare the perception of the alarm handling process, response time, false alarm rates between SPCS and a traditional patient care system (TPCS) and to describe nurses' user experience of SPCS.

\section{Methods}

\section{Aim, design and setting}

This study aimed to describe the implementation and experience of an innovative smart patient care system. In SPCS, all alarms can be routed to nurses' mobile phones, allowing for immediate communication and three-stage bed-exit alerts. This study applied a cross-sectional descriptive design. We recruited nurses from four wards of the Gastroenterology and Hepatology Department of a medical center in Taiwan in 2018. It was a convenient sample as this department initiated a purchase of the smart system due to an increasing fall rates and the high false alarm rates of the traditional system, providing a good opportunity for us to explore the user experience of an innovative patient care system. The inclusion criteria were nurses who worked in the Gastroenterology and Hepatology Department, were over 20 years old, and spoke Chinese or Taiwanese. The exclusion criteria were nurses with working experience in the present department for less than 3 months. Nurses from four wards were recruited.

\section{Instruments}

Among the four wards of the Gastroenterology and Hepatology Department, one ward had adopted an SPCS, while the other three used the TPCS. The TPCS had been the patient care system used in the study site for approximately two decades. The smart patient care system was introduced into one ward of the Gastroenterology and Hepatology Department in 2017, and all nurses in that ward were thereafter trained to use this system. A comparison between the SPCS and TPCS is presented in Fig. 1. In general, both the TPCS and SPCS are systems that nurses use to receive and handle nurse calls or bed-exit alerts. When patients press the call button, their room door light turns on, and their bed number is shown simultaneously on monitors in the corridor and nursing station, with an alarm sound raised. The display methods of bed-exit alerts are the same as those of a normal call in the TPCS. In the SPCS ward, all monitors in the corridor or nursing station not only show the bed number but also the purpose of the 


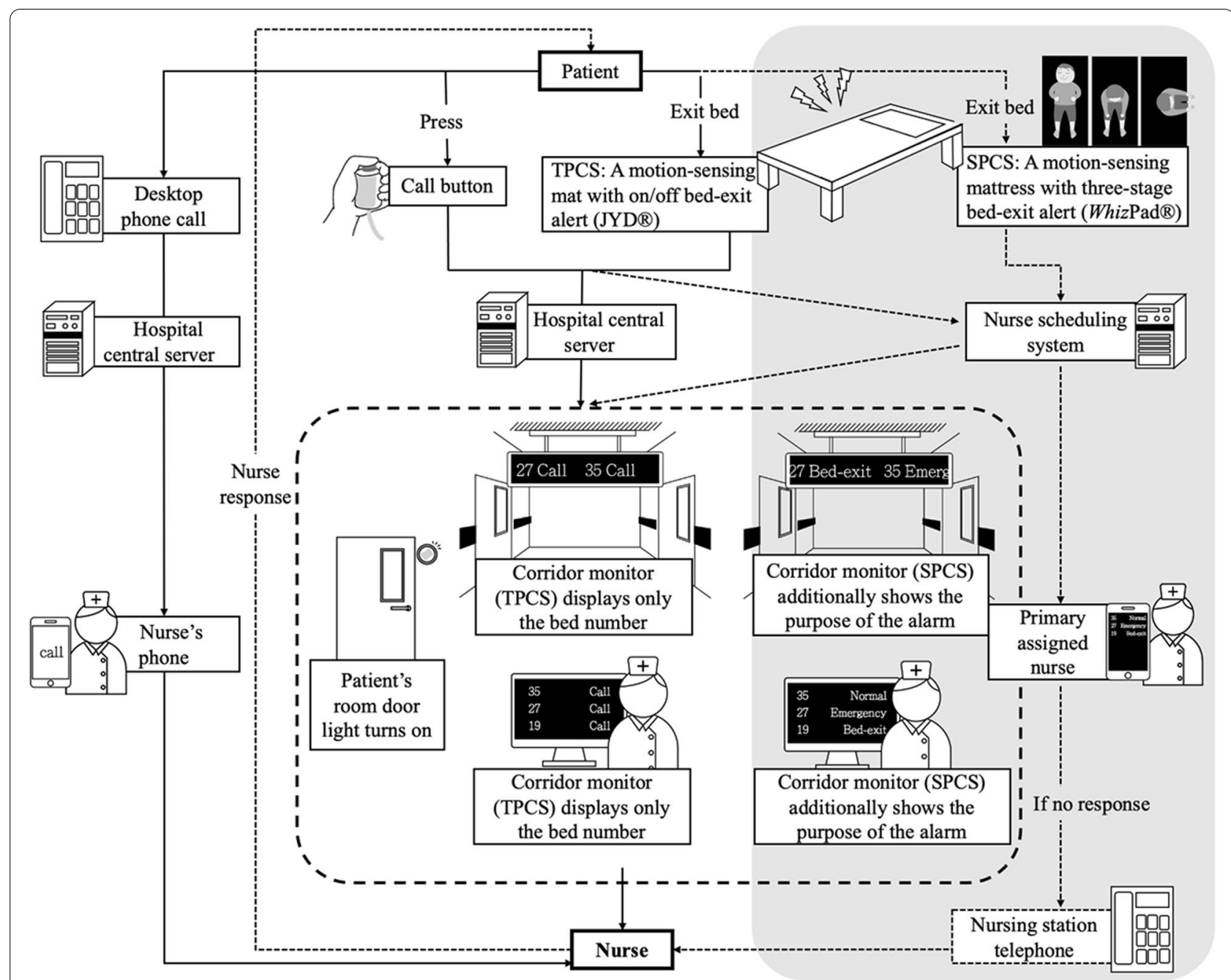

Fig. 1 Comparison of the alarm signal pathway between the SPCS and the TPCS (the additional functions of the SPCS are in the gray area)

alert, such as normal, emergency, bed-exit, and desktop phone call, to assist nurses in prioritizing and arranging actions. Patients can press whichever button for proper assistance according to their situations. For example, they can press the emergency call button to call for the nurses' immediate assistance if they decide it is an urgent situation.

A bed-exit alert is used for patients at risk of falling. In the TPCS wards, a movable sensing mat $\left(\mathrm{JYD}^{\circledR}\right)$ is used for bed-exit alerts, which are shown in the same way as a normal nurse call, without displaying the purpose as bed-exit. The bed-exit alert of this movable mat is only triggered when a patient leaves the mat. In comparison, the SPCS incorporates a motion-sensing mattress $\left(\right.$ Whiz $\left.\mathrm{Pad}^{\circledR}\right)$ that applies a machine learning method that can identify users' real-time positions, including on-bed, bed-edge, and off-bed positions.
With these three-stage alerts, nurses can be notified when a patient initiates a departure from his/her bed as early as when he/she begins to sit up in bed. Furthermore, in the SPCS ward, the bed-exit alert can be stopped at the patient's bedside, while in the TPCS wards, this alarm can be stopped remotely at nursing stations.

In addition, all SPCS alarms are additionally routed to nurses' mobile phones so that they can receive all messages immediately when they are on duty. The information exchange system in the SPCS is also connected to the scheduling system in the hospital so that only nurses on duty and primarily assigned to a certain patient receive such alarms. When a nurse receives such an alarm, he/ she can directly speak to patients when necessary via phone, and patients hear him/her through the speaker near their call button/bed. 


\section{Study procedure}

In terms of attitudes toward alarms, all the nurses from both the TPCS and SPCS wards were asked to choose the most annoying, cumbersome, time-consuming, and easily ignorable alarm. Nurses who worked in the SPCS ward were asked about their attitude toward and experience of how this system has helped them handle patient calls after using the system for 3 months or more. We developed a questionnaire for the user experience assessment since we failed to find an appropriate one in the existing literature. The questionnaire was then finalized after collecting experts' opinions. The items included in the questionnaire could be divided into two categories. The first part was asking nurses to evaluate the specific functions of SPCS including the immediate communication via phone, three-stage bed-exit alert, event presentation, and the interface. The other part of items included care efficiency, the awareness of patients' in-time situation, care quality, and working stress. We also asked nurses to specify their level of agreement or disagreement with the user experience statement using a 5-point Likert scale (strongly disagree, disagree, neutral, agree, and strongly agree) [27]. To compare nurses' agreement levels for different statements, a weighted arithmetic mean was calculated. In addition to the subjective attitudes and using experiences, we observed the frequency of false alarms and the response time to alarms by a trained research nurse. Each nurse was observed two to three times on their responses to the alarms. The research nurse tracked the exact time of an alarm from ringing to being handled with a timer. A total of 230 alarms were observed with 120 alarms from the TPCS wards and 110 alarms from the SPCS ward. For each alarm, the research nurse recorded the alarm type, bed number, the responsible nurse, and the handling time for further analysis.

\section{Analysis}

A descriptive analysis was conducted to describe the characteristics of participants using the mean, frequency, and percentage depending on the variables. For the linear variables including age, total working experience as a nurse, and working experience in the current department, t-tests were applied to compare the mean between TPCS and SPCS groups. For the comparison of sex between two groups, a Chi-square test was conducted. As for the other categorical variables including education level, job titles, and clinical nursing ladder, we used Fisher's exact tests as one of the cells contained less than five cases. The clinical nursing ladder was categorized as $\mathrm{N}$ (less than 1 year of clinical experience and has not obtained any level of clinical nursing certificate), N1, N2, N3, and N4, according to the clinical nursing ladder system [28]. Evidence suggests that advanced nurses (N3 and N4) have a better awareness of, beliefs in, attitudes toward, knowledge of, skills in, and behaviors of evidence-based practice than do new nurses (N, N1, and N2) [29]. Chi-square tests, Fisher's exact tests, and t-tests were also conducted to compare the frequency of false alarms and response time to alarms. All data analyses were performed using the statistical software package Stata Statistical Software: Release 16 (College Station, TX: StataCorp LLC) [30]. A nominal significance level of 0.05 and power of $80 \%$ were used throughout the analysis.

\section{Results}

Eighty-two nurses from all four wards of the Gastroenterology and Hepatology Department were recruited and analyzed in this study (Fig. 2). Fifty-seven nurses were from the TPCS wards, and 25 nurses were from the SPCS ward. The characteristics of the participants are presented in Table 1 . The average age was approximately 30 years old, and $85 \%$ of participants were female. Their average working experience in nursing was 6.8 years in total and 3.7 years in their current department. A total of $64.6 \%$ of the nurses were contract nurses, and $19.5 \%$ of them were registered nurses. Approximately $98.8 \%$ of the nurses had received a bachelor's degree or above. There are slight differences in the characteristics between nurses from the TPCS and SPCS wards, which, however, are without statistical significance.

Nurses' attitudes toward different alarms are presented in Table 2. The most annoying alarm was stated as being the emergency call alarm in both the TPCS and SPCS wards, with an average of approximately $60 \%$ of nurses agreeing to this statement, and 33\% of them considered the bed-exit alert as the second most annoying alarm. For the most cumbersome alarm, over two-thirds of nurses in the TPCS wards considered the emergency call alarm the most cumbersome alarm, while the most cumbersome alarm perceived by nurses from the SPCS ward was the bed-exit alert (44\%). In addition, less than $2 \%$ of nurses from the TPCS wards considered none of the alarms cumbersome, while $16 \%$ of nurses from the SPCS ward held such thoughts. These differences were statistically significant.

Similarly, half of the nurses from the TPCS wards considered the emergency call alarm to be the most timeconsuming alarm to which to respond, while it was the bed-exit alert that nurses from the SPCS ward rated as the most time-consuming alarm. In total, approximately one-fourth of nurses from the SPCS ward did not consider any alarm as being time-consuming to which to respond, while this percentage was only $3.5 \%$ in the TPCS group. These differences are also statistically significant. There is a large difference regarding the attitudes toward the most easily ignorable alarm in the TPCS and 


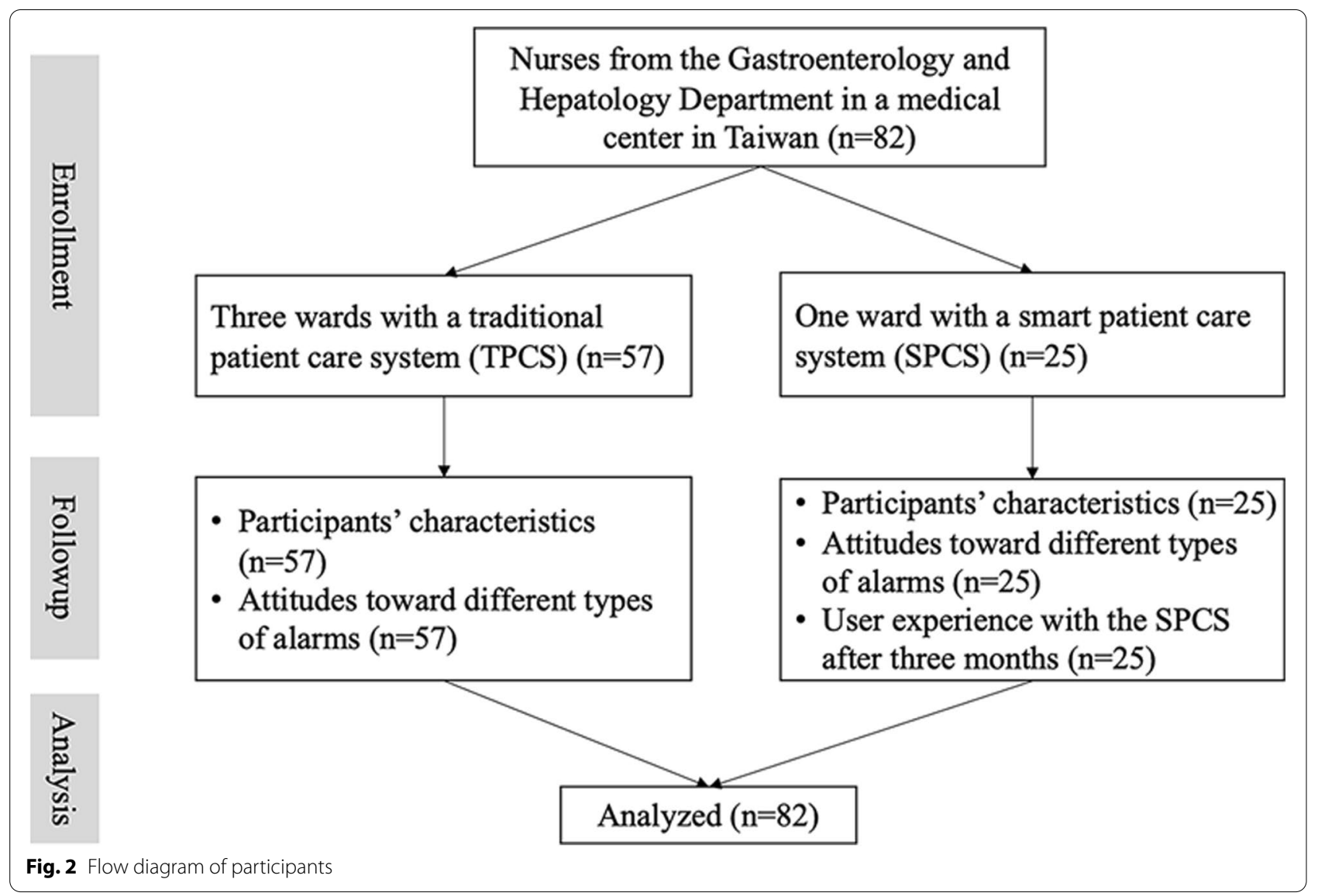

SPCS groups. Fifty-six percent of nurses from the TPCS wards considered the bed-exit alert to be the most easily ignorable alarm, and this rate was reduced to $32 \%$ in the SPCS ward. Furthermore, almost half of nurses (48\%) considered no specific alarm to be easily ignorable with all the functions in the SPCS ward, while this proportion was only $14 \%$ in the TPCS wards.

Among the nurses in the SPCS ward $(n=25)$, we further investigated their user experience of this system with a 5-point Likert scale (Table 3). The agreement level was scored from 1 (strongly disagree) to 5 (strongly agree). The most helpful function of the SPCS was immediate communication via phone when compared with the TPCS, with a weighted average score of $3.92 / 5$, and $52 \%$ of nurses strongly agreed that this function was helpful. The second highly ranked function was the three-stage bed-exit alert, with an average score of $3.68 / 5$, and approximately $24 \%$ of nurses strongly agreed that this function was helpful. Regarding other specific functions of the SPCS, $52 \%$ of nurses agreed that the awareness of patients' in-time situations was increased, 56\% agreed that the event presentation was easy to understand, and $44 \%$ agreed that the interface was easy to use. In general, nurses found that care efficiency and quality were improved, the SPCS was better than the TPCS, and the stress caused by patient care was reduced.

A total of 230 alarms from patient pressing the call buttons or the automatic bed-exit alerts were observed with 120 alarms from the TPCS wards and 110 alarms from the SPCS ward. The average response time in TPCS was $145.66 \mathrm{~s}$ while it was $59.02 \mathrm{~s}$ in the SPCS $(P<.001)$. In other words, the average response time was reduced by $59.48 \%$ in the SPCS ward in comparison with that in the TPCS wards. The impact of SPCS on the difference in the response time, however, should be interpreted with caution as other factors may influence the result. Among the 110 alarms in the SPCS ward, none of them were false bed-exit alarms. In comparison, among 120 alarms in the TPCS wards, 42 of them were false bed-exit alarms. The false alarm rate in SPCS and TPCS was 0, and 35\%, respectively, with statistical significance $(P<.001)$. In addition to the specification of alarm sources, SPCS allowed nurses to receive the signal by their smartphone. In this study, we found that $30.91 \%$ of alarms in SPCS were processed because nurses received the information by their phone. 
Table 1 Participant characteristics

\begin{tabular}{|c|c|c|c|c|}
\hline & $\begin{array}{l}\text { Total } \\
(N=82)\end{array}$ & $\begin{array}{l}\text { TPCS } \\
(N=57)\end{array}$ & $\begin{array}{l}\text { SPCS } \\
(N=25)\end{array}$ & $P$-value \\
\hline Age (mean) & 29.76years & 30.32 & 28.48 & .349 \\
\hline Total working experience as a nurse (mean) & 6.8 years & 7.40 & 5.56 & .347 \\
\hline Working experience in current department (mean) & 3.7years & 3.91 & 3.36 & .680 \\
\hline \multicolumn{5}{|l|}{ Sex } \\
\hline Male & $12(14.6 \%)$ & $7(12.3 \%)$ & $5(20.0 \%)$ & \multirow[t]{2}{*}{.363} \\
\hline Female & $70(85.4 \%)$ & $50(87.7 \%)$ & $20(80.0 \%)$ & \\
\hline \multicolumn{4}{|l|}{ Education level } & \multirow[t]{5}{*}{.436} \\
\hline Associate's degree & $1(1.2 \%)$ & $0(0.0 \%)$ & $1(4.0 \%)$ & \\
\hline Postgraduate 2 years (PGY2) & $18(22.0 \%)$ & $14(24.6 \%)$ & $4(16.0 \%)$ & \\
\hline Bachelor's degree & $57(69.5 \%)$ & $39(68.4 \%)$ & $18(72.0 \%)$ & \\
\hline Master's degree & $6(7.3 \%)$ & $4(7.0 \%)$ & $2(8.0 \%)$ & \\
\hline \multicolumn{5}{|l|}{ Job titles } \\
\hline Administrative assistant & $1(1.2 \%)$ & $0(0.0 \%)$ & $1(4.0 \%)$ & \multirow[t]{6}{*}{.748} \\
\hline Contract nurse & $53(64.6 \%)$ & $36(63.2 \%)$ & $17(68.0 \%)$ & \\
\hline Registered nurse & $16(19.5 \%)$ & $12(21.1 \%)$ & $4(16.0 \%)$ & \\
\hline Practical nurse & $6(7.3 \%)$ & $4(7.0 \%)$ & $2(8.0 \%)$ & \\
\hline Assistant head nurse & $4(4.9 \%)$ & $3(5.3 \%)$ & $1(4.0 \%)$ & \\
\hline Head nurse & $2(2.5 \%)$ & $2(3.5 \%)$ & $0(0.0 \%)$ & \\
\hline \multicolumn{5}{|l|}{ Clinical nursing ladder } \\
\hline N & $20(24.4 \%)$ & $15(26.3 \%)$ & $5(20.0 \%)$ & \multirow[t]{5}{*}{.257} \\
\hline N1 & $29(35.4 \%)$ & $18(31.6 \%)$ & $11(44.0 \%)$ & \\
\hline N2 & $19(23.2 \%)$ & $16(28.1 \%)$ & $3(12.0 \%)$ & \\
\hline N3 & $7(8.5 \%)$ & $3(5.3 \%)$ & $4(16.0 \%)$ & \\
\hline N4 & $7(8.5 \%)$ & $5(8.8 \%)$ & $2(8.0 \%)$ & \\
\hline
\end{tabular}

\section{Discussion}

This study examined nurses' attitudes toward different alarms as well as their user experience of a smart patient care system. Emergency calls are treated as the most annoying alarm in both the TPCS and SPCS wards and as the most cumbersome and time-consuming alarm in the TPCS wards. Bed-exit alerts were perceived as the most cumbersome and time-consuming alarm in the SPCS ward. The SPCS successfully attracted the attention of nurses to bed-exit alerts due to its advantages, including the specification of alarm purposes, immediate communication with patients, and the three-stage bed-exit alert leading to the actual action of responding to it. Although the bed-exit alert was treated as the most cumbersome and time-consuming alarm, it was not considered the most annoying alarm, which may be because nurses want to be notified by this kind of alarm so that they can take active action to assist patients at high risk of falling. The most easily ignorable alarm was the bed-exit alert (56\%) in the TPCS wards, while it was reduced to $32 \%$ in the SPCS ward. In addition, $48 \%$ of nurses claimed that none of the alarms were easily ignorable with the SPCS. Regarding the user experience of the SPCS, the most helpful function of the SPCS was considered to be immediate communication via phone, followed by the threestage bed-exit alert. The advantages of the SPCS over the TPCS perceived by nurses include an improvement of care efficiency, an increase in the awareness of patients' in-time situation and care quality, an easily understandable event presentation, an easy-to-use interface, and a reduction in stress caused by caring for patients.

Patient care system alarms, by nature, are a source of interruption for nurses [4, 21, 24]. These interruptions have been shown as a potential contributory factor leading to medical errors in clinical environments [31-33]. Many studies have tried to reduce medical errors by reducing the frequency of interruptions, the effect and safety of which, however, remain questionable [21, 34, $35]$. The main reason for this may be due to the complex nature of interruptions in hospital settings, in which not all interruptions are undesirable [14, 17, 20, 24]. Moreover, patients think that it is essential that their requests are taken seriously and that they can receive support whenever needed [2, 7]. Studies have shown that a patient care system helps patients feel safe and contributes to their successful recovery [2, 3]. Interruptions 
Table 2 Nurses' attitudes toward different patient care system alarms $(\mathrm{N}=82)$

\begin{tabular}{lllll}
\hline & Total & $\begin{array}{l}\text { TPCS } \\
(\boldsymbol{n}=\mathbf{5 7})\end{array}$ & $\begin{array}{l}\text { SPCS } \\
(\boldsymbol{n}=\mathbf{2 5})\end{array}$ & P-value \\
\hline Most annoying alarm & & & & \\
Normal call & $6(7.3 \%)$ & $4(7.0 \%)$ & $2(8.0 \%)$ & .868 \\
Emergency call & $49(59.8 \%)$ & $33(57.9 \%)$ & $16(64.0 \%)$ & \\
Bed-exit alert & $27(32.9 \%)$ & $20(35.1 \%)$ & $7(28.0 \%)$ & \\
Desktop phone call & $0(0.0 \%)$ & $0(0.0 \%)$ & $0(0.0 \%)$ & \\
None & $0(0.0 \%)$ & $0(0.0 \%)$ & $0(0.0 \%)$ & \\
Most cumbersome alarm & & & & \\
Normal call & $6(7.3 \%)$ & $4(7.0 \%)$ & $2(8.0 \%)$ & .005 \\
Emergency call & $47(57.3 \%)$ & $39(68.4 \%)$ & $8(32.0 \%)$ & \\
Bed-exit alert & $23(28.1 \%)$ & $12(21.1 \%)$ & $11(44.0 \%)$ & \\
Desktop phone call & $1(1.2 \%)$ & $1(1.8 \%)$ & $0(0.0 \%)$ & \\
None & $5(6.1 \%)$ & $1(1.8 \%)$ & $4(16.0 \%)$ & \\
Most time-consuming alarm & & & \\
Normal call & $12(14.6 \%)$ & $7(12.3 \%)$ & $5(20.0 \%)$ & .003 \\
Emergency call & $34(41.5 \%)$ & $29(50.1 \%)$ & $5(20.0 \%)$ & \\
Bed-exit alert & $26(31.7 \%)$ & $18(31.6 \%)$ & $8(32.0 \%)$ & \\
Desktop phone call & $2(2.4 \%)$ & $1(1.8 \%)$ & $1(4.0 \%)$ & \\
None & $8(9.8 \%)$ & $2(3.5 \%)$ & $6(24.0 \%)$ & \\
Most easily ignorable alarm & & & \\
Normal call & $10(12.2 \%)$ & $8(14.0 \%)$ & $2(8.0 \%)$ & .024 \\
Emergency call & $3(3.6 \%)$ & $2(3.5 \%)$ & $1(4.0 \%)$ & \\
Bed-exit alert & $40(48.8 \%)$ & $32(56.1 \%)$ & $8(32.0 \%)$ & \\
Desktop phone call & $9(11.0 \%)$ & $7(12.3 \%)$ & $2(8.0 \%)$ & \\
None & $20(24.4 \%)$ & $8(14.0 \%)$ & $12(48.0 \%)$ & \\
\hline
\end{tabular}

such as alarms also play an important role in transferring requests and information in a timely manner and enhancing patient care quality $[5,14,22,36]$.

Nurses have a variety of clinical and administrative tasks and have to decide whether to prioritize responding to an alarm over the ongoing activity [37]. There are different levels of importance or urgency in which nurses find themselves when receiving an alarm [24]. Before actually responding to an alarm, nurses need to assess the situation, figure out how to respond, and decide what to do [26]. Therefore, a resilient patient care system is necessary to help nurses adjust their work to various work conditions [38]. One of the critical functions that a resilient patient care system should have is the capacity through which nurses can access an alarm immediately wherever and whenever needed. In the TPCS wards in our study, if patients press the nurse call button or leave their bed, thus setting off the bed-exit alert, nurses can only receive information on the bed number of the alert from a fixed display such as the patient's room door light and display monitors in the corridor or nursing station. Thus, it is highly likely that nurses will not see this fixed display if they are not located near it.

Studies have shown that nurses tend to perceive alarms as interruptions rather than means through which to communicate with patients [16]. In the SPCS ward of our study, all alarms are routed to nurses' smartphones, and they are supposed to carry their phones around to receive any nurse alarm whenever and wherever necessary. This smartphone integration in the SPCS is able to notify highly mobile nurses when they are not located near a fixed display [23]. The results from the present study showed a significant reduction in the rate of the most easily ignorable alarm perceived by nurses from $86 \%$ in the TPCS wards to $52 \%$ in the SPCS ward. On the other hand, there were still half of the nurses who thought the SPCS alarms could be ignored somehow. Unfortunately, we failed to collect data on reasons that could lead to this result which should be further investigated in the future. The incorporation with nurses' smartphones in the SPCS helps reduce the limitation of location when receiving alarms and therefore, may increase the frequency of using the patient care system. Evidence has shown that a

Table 3 Nurses' experience using the SPCS $(N=25)$

\begin{tabular}{|c|c|c|c|c|c|c|}
\hline & \multicolumn{6}{|c|}{ Agreement level } \\
\hline & $\begin{array}{l}\text { Strongly } \\
\text { disagree }\end{array}$ & Disagree & Neutral & Agree & $\begin{array}{l}\text { Strongly } \\
\text { agree }\end{array}$ & $\begin{array}{l}\text { Weighted } \\
\text { average }\end{array}$ \\
\hline The immediate communication via phone is helpful & $1(4 \%)$ & $3(12 \%)$ & $6(24 \%)$ & $2(8 \%)$ & $13(52 \%)$ & 3.92 \\
\hline The three-stage bed-exit alert is helpful & $0(0 \%)$ & $2(8 \%)$ & $10(40 \%)$ & $7(28 \%)$ & $6(24 \%)$ & 3.68 \\
\hline Care efficiency is improved & $0(0 \%)$ & $1(4 \%)$ & $8(32 \%)$ & $16(64 \%)$ & $0(0 \%)$ & 3.60 \\
\hline The awareness of patients' in-time situation is increased & $0(0 \%)$ & $0(0 \%)$ & $12(48 \%)$ & $13(52 \%)$ & $0(0 \%)$ & 3.52 \\
\hline Care quality is increased & $0(0 \%)$ & $1(4 \%)$ & $12(48 \%)$ & $12(48 \%)$ & $0(0 \%)$ & 3.44 \\
\hline The event presentation is easy to understand & $0(0 \%)$ & $3(12 \%)$ & $8(32 \%)$ & $14(56 \%)$ & $0(0 \%)$ & 3.44 \\
\hline The interface is easy to use & $0(0 \%)$ & $0(0 \%)$ & $14(56 \%)$ & $11(44 \%)$ & $0(0 \%)$ & 3.44 \\
\hline The stress caused by caring for patients is reduced & $1(4 \%)$ & $2(8 \%)$ & $15(60 \%)$ & $7(28 \%)$ & $0(0 \%)$ & 3.12 \\
\hline
\end{tabular}


higher frequency of patient care system usage is associated with a lower hospital fall incidence, higher patient satisfaction, and increased intention to use the patient care system [39].

Moreover, an SPCS may also raise the nurse interruptions and their work burden. As a resilient system, the frequency of interruptions does not necessarily increase in the SPCS ward and may even decrease by engaging with the nurse scheduling system data. This function allows nurses to only receive alarms from patients who have been primarily assigned to them during their shift. Studies have shown that nurses are more likely to prioritize an alarm if they have primary responsibility for the patient who is calling $[14,36]$. Therefore, routing alarms to primarily assigned nurses by integration with the nursing scheduling system helps nurses receive fewer but more relevant alarms, which is better for their decisionmaking process in terms of the prioritization of responding to alarms. In addition, the SPCS is able to transfer a signal to the nursing station if no one responds after $20 \mathrm{~s}$ to ensure that the alarm is received and addressed. In practical situations, nurses will also choose to pass their work phone to another colleague before they undertake a scheduled task requiring high concentration that cannot be disrupted. This approach is practical yet not the best solution. It would be more convenient if the patient care system were to allow nurses to formally hand over their responsibility to secondarily assigned nurses in the system just by clicking his/her name in the app when necessary. This function was not integrated into the SPCS during the study period, and thus, it is suggested as a direction for future research. Studies have consistently shown that formal responsibility handover helps nurses focus on ongoing tasks [14, 24, 36].

It is suggested that a patient care system capable of showing the purpose of an alarm helps nurses save time struggling and improve patient care accordingly [4, 7 , 21]. Such a patient care system should be able to display an alarm as a normal call, emergency call, or any other alarms needed in nursing practices. Currently, few patient care systems in hospitals have such functions, and limited evidence has been found in the existing scientific literature $[6,40]$. Studies have shown that an alarm is easier to ignore, especially when the purpose of the alarm is not specified $[22,24]$. There are four major purposes of alarms at our study site: a normal call, an emergency call, a bed-exit alert, and a desktop phone call. The SPCS can display each alarm's purpose on monitors or phones, while nurses in the TPCS wards were not able to differentiate between normal calls and bed-exit alerts. Given the higher frequency of normal calls, it is easier for nurses in the TPCS wards to ignore bed-exit alerts compared to nurses in the SPCS ward. The rate of nurses' perception of missing a bed-exit alert is approximately $56 \%$ in the TPCS wards, while this rate was reduced to $32 \%$ in the SPCS ward.

The results from studies investigating the purposes of alarms show that only a small number of such alarms require immediate attention and handling by nurses $[4,7,21]$. Moreover, nurses are suggested to prioritize responding to alarms to improve patient-centered care quality and reduce adverse events [6, 7]. Instead of focusing on fostering nurses' attitudes toward alarms, which has been shown to have an unoptimistic effect [41], more effort should be made to develop resilient technologies that can support nurses in better prioritizing multiple patient care duties $[6,42]$. The concept of resilience engineering is also applied in the SPCS introduced at our study site with specifying alarm purposes and allowing for immediate communication with patients directly via phone. Normally it is difficult for nurses to decide whether the alarm is so urgent that they should abort the ongoing task based on limited information. In the SPCS ward, nurses can directly communicate with a patient via phone for more details on the purpose of the alarm and may even ask him/her to wait for a short period for their assistance if the situation allows. The results from our study showed that over half of nurses agreed that their awareness of patients' in-time situations was increased via this system. In addition, the statement "immediate communication via phone is helpful" has the highest agreement level among all the innovative functions of the SPCS. The function of immediate communication via phone in SPCS helps nurses respond to patients' requests or needs in a timely manner and to have a better capacity to prioritize multiple clinical tasks.

Patient safety is an important aspect of a patient care system, from the perspective of both nurses [6] and patients [7]. Patient falls are serious patient safety problems in hospitals, and fall prevention is one of the most important expectations of the patient care system [11, 43]. Hospital falls commonly occur between $5 \mathrm{pm}$ and $7 \mathrm{am}$ in a patient's room when staffing levels are lower, and a large number of falls are related to getting in and out of bed [13]. In clinical practice, it is common to use bed-exit detection systems, such as mattresses/pads, cameras, and wearable devices, to help notify nurses about bed-exit situations for patients who are at high risk of falling [44, 45]. The effect of these systems on fall prevention, however, is inconclusive $[46,47]$. One of the major concerns of the bed-exit system is that there is not enough time for nurses to receive an alert and to then provide actual assistance before the patient leaves his/her bed [25, 48]. In our study, the SPCS incorporated a motion-sensing mattress that used a machine learning algorithm that allowed for three-stage bed-exit 
notification so that nurses could receive the alert about the patient's intention to leave his/her bed as early as when he/she sits up in bed. In addition, nurses could ask patients to wait for a short period for assistance in leaving bed with the immediate communication function of the SPCS when they found themselves unable to provide assistance immediately. With the three-stage bed-exit notification and immediate communication functions, the SPCS can help nurses respond to and assist patients at risk of falling when they intend to leave bed in a timely manner. There is also a difference in the administrational response process between the SPCS and TPCS wards. In the TPCS wards, once the bed-exit alert is activated, nurses can simply stop it by pressing a button at the nursing station, while in the SPCS ward, they are required to stop it at the patient's bedside. Evidence suggests that responding to a situation implies dealing with the actual situation, especially when the outcome is related to patient safety [24,38]. Although the response process in the SPCS ward may bring about some inconvenience for nurses, it helps ensure that patients' needs are actually being addressed. Therefore, we observed that although the rate of nurses perceiving bed-exit alerts as the most cumbersome type of alarm was higher in the SPCS ward than in the TPCS wards, the proportion of them considering such alerts as the most annoying alarm decreased. In addition, over half of the nurses in the present study agreed that the bed-exit alert was helpful.

False alarms have been commonly reported in the existing bed-exit alarm systems. It is shown that false alarms have counted for above $80 \%$ of all bed-exit alarms leading to alarm fatigue which can increase the nursing staff's work burden and lower their willingness to use the system and finally result in falling [49-51]. The excessive false alarms may lead the alarm fatigue in which nursing staff would occasionally ignore the alarms. A multicenter study showed that over $70 \%$ of the monitor alarms were false alarms and only $5.9 \%$ of all alarms received responses from nursing staff [52]. In addition, false alarms may frequently disrupt patients' sleep and negatively influence their recovery [53]. In this study, we observed 35.2\% of false alarms in TPCS and 0\% in SPCS. The high predictive positive value of SPCS significantly improves nursing staff's willingness to use the system which may be another reason that SPCS has a positive effect on fall prevention $[54,55]$.

This study has some limitations. First, the patient care requirements and nurse-patient interactions vary among different departments in hospitals [36]. In our study, the smart patient care system was only introduced in one ward, limiting the study in its generalizability to different settings. Second, the small sample size limits the generalizability of this study. We collected data on 82 nurses' attitudes toward patient care systems were collected, while only 25 nurses used the SPCS and gave us feedback on their user experience. This sample size may be relatively small compared with those of other studies. There are no consistent recommendations for sample size in usability studies, with some suggesting that five is sufficient, and others suggesting that there should be ten or more [56]. Third, a patient care system involves both nurses and patients [2, 22]. However, we only focused on the perspectives and experiences of nurses. Future work should also collect data from patients and their family members. Lastly, many factors can affect nurses' response time such as ward architecture, route length, conditions of nurses [36, 54]. These potential influencing factors were not taken into analysis in the present study which could cause bias for the impact of the SPCS on the attitude, experience, and response time of nurses.

\section{Conclusions}

Nurses are required to handle multiple tasks in clinical practice, and they tend to consider patient care system alarms as being annoying, cumbersome, time-consuming, and easily ignorable. Conversely, alarms play an important role in the transfer of patient requests, and responding to them in a timely manner is associated with reduced injuries and increased patient satisfaction [39]. A resilient patient care system is needed to help nurses prioritize their responses to alarms and cope with them while also handling other nursing duties. These patient care systems should be able to specify alarm purposes, such as normal, emergency, and bed-exit alarms, to help nurses quickly judge the level of urgency; route the alarm directly to the mobile phone/device carried by the primary assigned nurse of the calling patient to reduce the frequency of alarms and increase the response rate; be capable of immediate communication to help nurses obtain more details of the calling purpose or even buy some more time to provide assistance; and include inadvance bed-exit alerts that provide nurses with sufficient time to provide assistance. Future product development for patient care systems should focus on the capacity that allows nurses to make more informed prioritization decisions between responding to alarms and the ongoing tasks at hand and finally assist them in adjusting their work in various situations to improve work efficiency and care quality. Further research is also needed on the effect of patient care systems on nurses' work efficiency and patient safety outcomes, such as fall prevention.

Abbreviations

SPCS: Smart patient care system; TPCS: Traditional patient care system. 


\section{Acknowledgements}

We would like to thank all the participants who voluntarily participated in the study.

\section{Authors' contributions}

All authors made significant contributions to the manuscript. The study was conceived by MHW and SL. MHW and SL collected the data. DLB, CJC, and YLH contributed to the analysis. The manuscript was drafted by MHW, DLB, SL, CJC, and YLH. All authors read and approved the final manuscript.

\section{Funding}

Taipei Veterans General Hospital Founded this study (Grant V107A-029), but did not have any role in the study design, the collection, analysis, and interpretation of the data, in the writing of the paper, nor in the decision to submit the paper for publication.

\section{Availability of data and materials}

The dataset used during the current study is available from the corresponding author on reasonable request.

\section{Declarations}

\section{Ethics approval and consent to participate}

All methods were performed in accordance with the Declaration of Helsinki. The study procedures were reviewed and approved by the Institutional Review Board, Taipei Veterans General Hospital, Taiwan with approval number 2017-07-017B. Written informed consent was obtained from each participant.

\section{Consent for publication}

Not applicable.

\section{Competing interests}

The authors declare that they have no competing interests.

\section{Author details}

${ }_{1}^{1}$ Department of Nursing, Taipei Veterans General Hospital, Taipei, Taiwan. ${ }^{2}$ School of Nursing, National Yang Ming Chiao Tung University, Taipei, Taiwan. ${ }^{3}$ Gerontechnology Research Center, Yuan Ze University, Taoyuan, Taiwan. ${ }^{4}$ Department of Medicine, Taipei Veterans General Hospital, Taipei, Taiwan. ${ }^{5}$ Mechanical Engineering Department, Yuan Ze University, Taoyuan, Taiwan.

Received: 7 August 2021 Accepted: 18 January 2022

Published online: 29 January 2022

\section{References}

1. Nightingale F, Vicinus M. Ever yours, Florence Nightingale: selected letters. Cambridge: Harvard University Press; 1990

2. Lasiter S. "The button" initiating the patient-nurse interaction. Clin Nurs Res. 2014;23(2):188-200.

3. Lasiter S. Older adults' perceptions of feeling safe in an intensive care unit. J Adv Nurs. 2011;67(12):2649-57.

4. Meade CM, Bursell AL, Ketelsen L. Effects of nursing rounds: on patients' call light use, satisfaction, and safety. Am J Nurs. 2006;106(9):58-70.

5. Rivera AJ. A socio-technical systems approach to studying interruptions: understanding the interrupter's perspective. Appl Ergon. 2014:45(3):747-56.

6. Tzeng H-M. Perspectives of staff nurses of the reasons for and the nature of patient-initiated call lights: an exploratory survey study in four USA hospitals. BMC Health Serv Res. 2010;10(1):52.

7. Tzeng H-M. Perspectives of patients and families about the nature of and reasons for call light use and staff call light response time. Medsurg Nurs. 2011;20(5):225-34.

8. Ambutas S. Continuous quality improvement. Fall reduction and injury prevention toolkit: implementation on two medical-surgical units. Medsurg Nurs. 2017;26(3) http://search.ebscohost.com/login.aspx?direct= true $\& \mathrm{db}=\mathrm{as} \times \& A N=123430220 \& l a n g=$ zh-tw\&site $=$ eds-live (Accessed February 2021)

9. Dunne TJ, Gaboury I, Ashe MC. Falls in hospital increase length of stay regardless of degree of harm. J Eval Clin Pract. 2014;20(4):396-400.
10. Florence CS, Bergen G, Atherly A, Burns E, Stevens J, Drake C. Medical costs of fatal and nonfatal falls in older adults. J Am Geriatr Soc. 2018;66(4):693-8.

11. Bouldin ED, Andresen EM, Dunton NE, Simon M, Waters TM, Liu M, et al. Falls among adult patients hospitalized in the United States: prevalence and trends. J Patient Saf. 2013;9(1):13.

12. Rosenthal MB. Nonpayment for performance? Medicare's new reimbursement rule. N Engl J Med. 2007:357(16):1573-5.

13. Ranasinghe D, Torres RS, Hill K, Visvanathan R. Low cost and batteryless sensor-enabled radio frequency identification tag based approaches to identify patient bed entry and exit posture transitions. Gait Posture. 2014;39(1):118-23.

14. Klemets J, Evjemo TE. Technology-mediated awareness: facilitating the handling of (un) wanted interruptions in a hospital setting. Int J Med Inform. 2014;83(9):670-82.

15. Kristiansen $L$, editor Nurse calls via personal wireless devices; some challenges and possible design solutions. 2011 24th International Symposium on Computer-Based Medical Systems; 2011: IEEE.

16. Deitrick L, Bokovoy J, Stern G, Panik A. Dance of the call bells: using ethnography to evaluate patient satisfaction with quality of care. J Nurs Care Qual. 2006:21(4):316-24.

17. Li SY, Magrabi F, Coiera E. A systematic review of the psychological literature on interruption and its patient safety implications. J Am Med Inform Assoc. 2012;19(1):6-12.

18. Tucker AL, Spear SJ. Operational failures and interruptions in hospital nursing. Health Serv Res. 2006;41(3p1):643-62.

19. Hall LM, Pedersen C, Fairley L. Losing the moment: understanding interruptions to nurses' work. J Nurs Adm. 2010;40(4):169-76.

20. Grundgeiger T, Sanderson P. Interruptions in healthcare: theoretical views. Int J Med Inform. 2009:78(5):293-307.

21. Torres SM. Rapid-cycle process reduces patient call bell use, improves patient satisfaction, and anticipates patient's needs. J Nurs Adm. 2007;37(11):480-2.

22. Klemets J, Toussaint P. Does revealing contextual knowledge of the patient's intention help nurses' handling of nurse calls? Int J Med Inform. 2016;86:1-9.

23. Bardram JE, Bossen C. Mobility work: the spatial dimension of collaboration at a hospital. Comput Supported Coop Work. 2005;14(2):131-60.

24. Klemets J, Evjemo TE. Understanding nurses' strategies to handle (un) wanted nurse calls: a resilience perspective. Comput Inform Nurs. 2017:35(6):289-99.

25. Kosse NM, Brands K, Bauer JM, Hortobágyi T, Lamoth CJ. Sensor technologies aiming at fall prevention in institutionalized old adults: a synthesis of current knowledge. Int J Med Inform. 2013;82(9):743-52.

26. Pariès J. Resilience and the ability to respond. In: Resilience engineering in practice. Florida: CRC Press; 2011. p. 3-8

27. Joshi A, Kale S, Chandel S, Pal DK. Likert scale: Explored and explained. British J Appl Sci Technol. 2015;7(4):396-403.

28. Hsu N, Chen BTH, LI L, Chen C, Cf L. The comparison of nursing competence pre-and postimplementing clinical ladder system. J Clin Nurs. 2005;14(2):264-5

29. Weng YH, Chen C, Kuo KN, Yang CY, Lo HL, Chen KH, et al. Implementation of evidence-based practice in relation to a clinical nursing ladder system: a National Survey in Taiwan. Worldviews Evid Based Nurs. 2015;12(1):22-30

30. StataCorp. Stata Statistical Software: Release 16. College Station, TX: StataCorp LLC; 2019.

31. Westbrook Jl, Woods A, Rob MI, Dunsmuir WT, Day RO. Association of interruptions with an increased risk and severity of medication administration errors. Arch Intern Med. 2010;170(8):683-90.

32. Westbrook JI, Coiera E, Dunsmuir WT, Brown BM, Kelk N, Paoloni R, et al. The impact of interruptions on clinical task completion. BMJ Qual Saf. 2010;19(4):284-9.

33. Prakash V, Koczmara C, Savage P, Trip K, Stewart J, McCurdie T, et al. Mitigating errors caused by interruptions during medication verification and administration: interventions in a simulated ambulatory chemotherapy setting. BMJ Qual Saf. 2014:23(11):884-92.

34. Rivera-Rodriguez A, Karsh B-T. Interruptions and distractions in healthcare: review and reappraisal. BMJ Qual Saf. 2010;19(4):304-12.

35. Raban $M Z$, Westbrook JI. Are interventions to reduce interruptions and errors during medication administration effective?: a systematic review. BMJ Qual Saf. 2014:23(5):414-21. 
36. Klemets JHM, Evjemo TE, Kristiansen L. Designing for redundancy: nurses experiences with the wireless nurse call system. Stud Health Technol Inform. 2013;192:328-32.

37. Woods DD, Wreathall J. Stress-strain plots as a basis for assessing system resilience. In: Hollnagel E, Nemeth CP, Dekker S, editors. Resilience engineering perspectives, Remaining sensitive to the possibility of failure, vol. 1. Aldershot, UK: Ashgate; 2008. p. 143-58.

38. Fairbanks RJ, Wears RL, Woods DD, Hollnagel E, Plsek P, Cook RI. Resilience and resilience engineering in health care. Jt Comm J Qual Patient Saf. 2014:40(8):376-83.

39. Tzeng H-M, Yin C-Y. Are call light use and response time correlated with inpatient falls and inpatient dissatisfaction? J Nurs Care Qual. 2009;24(3):232-42.

40. Galinato J, Montie M, Patak L, Titler M. Perspectives of nurses and patients on call light technology. Comput Inform Nurs. 2015;33(8):359.

41. Tzeng H-M. Perspectives of staff nurses toward patient-and familyinitiated call light usage and response time to call lights. Appl Nurs Res. 2011;24(1):59-63.

42. Hollnagel E, Woods DD, Leveson N. Resilience engineering: concepts and precepts. Farnham: Ashgate Publishing, Ltd; 2006.

43. Hempel S, Newberry S, Wang Z, Booth M, Shanman R, Johnsen B, et al. Hospital fall prevention: a systematic review of implementation, components, adherence, and effectiveness. J Am Geriatr Soc. 2013;61 (4):483-94.

44. Jähne-Raden N, Kulau U, Marschollek M, Wolf K-H. INBED: a highly specialized system for bed-exit-detection and fall prevention on a geriatric Ward. Sensors. 2019;19(5):1017.

45. Bruyneel M, Libert W, Ninane V. Detection of bed-exit events using a new wireless bed monitoring assistance. Int J Med Inform. 2011;80(2):127-32.

46. Shorr RI, Chandler AM, Mion LC, Waters TM, Liu M, Daniels MJ, et al. Effects of an intervention to increase bed alarm use to prevent falls in hospitalized patients: a cluster randomized trial. Ann Intern Med. 2012;157(10):692-9.

47. Wolf K-H, Hetzer K, Zu Schwabedissen H, Wiese B, Marschollek M. Development and pilot study of a bed-exit alarm based on a body-worn accelerometer. Z Gerontol Geriatr. 2013;46(8):727-33.

48. KwokT, Mok F, Chien WT, Tam E. Does access to bed-chair pressure sensors reduce physical restraint use in the rehabilitative care setting? J Clin Nurs. 2006;15(5):581-7.

49. Siebig S, Kuhls S, Imhoff M, Gather U, Schölmerich J, Wrede CE. Intensive care unit alarms - how many do we need? Crit Care Med. 2010;38(2):451-6.

50. Atzema C, Schull MJ, Borgundvaag B, Slaughter GR, Lee CK. ALARMED: adverse events in low-risk patients with chest pain receiving continuous electrocardiographic monitoring in the emergency department. A pilot study. Am J Emerg Med. 2006;24(1):62-7.

51. Tsien CL, Fackler JC. Poor prognosis for existing monitors in the intensive care unit. Crit Care Med. 1997;25(4):614-9.

52. Chambrin M-C, Ravaux P, Calvelo-Aros D, Jaborska A, Chopin C, Boniface B. Multicentric study of monitoring alarms in the adult intensive care unit (ICU): a descriptive analysis. Intensive Care Med. 1999;25(12):1360-6.

53. Matthews EE. Sleep disturbances and fatigue in critically ill patients. AACN Adv Crit Care. 2011;22(3):204-24.

54. Dugstad J, Sundling V, Nilsen ER, Eide H. Nursing staff's evaluation of facilitators and barriers during implementation of wireless nurse call systems in residential care facilities. A cross-sectional study. BMC Health Serv Res. 2020;20(1):1-13.

55. Murray GR, Cameron ID, Cumming RG. The consequences of falls in acute and subacute hospitals in Australia that cause proximal femoral fractures. J Am Geriatr Soc. 2007;55(4):577-82.

56. Schmettow M. Sample size in usability studies. Commun ACM. 2012;55(4):64-70.

\section{Publisher's Note}

Springer Nature remains neutral with regard to jurisdictional claims in published maps and institutional affiliations.

Ready to submit your research? Choose BMC and benefit from:

- fast, convenient online submission

- thorough peer review by experienced researchers in your field

- rapid publication on acceptance

- support for research data, including large and complex data types

- gold Open Access which fosters wider collaboration and increased citations

- maximum visibility for your research: over $100 \mathrm{M}$ website views per year

At BMC, research is always in progress.

Learn more biomedcentral.com/submissions 